\title{
Information and Digital Development of Higher Education in the Conditions of Innovatyzation Economy of Ukraine
}

\author{
KATERYNA KRAUS \\ Department of Management \\ Borys Grinchenko Kyiv University \\ Kyiv, 18/2 Bulvarno-Kudriavska St. \\ UKRAINE \\ NATALIIA KRAUS \\ Department of Finance and Economics \\ Borys Grinchenko Kyiv University \\ Kyiv, 18/2 Bulvarno-Kudriavska St. \\ UKRAINE \\ PETRO NIKIFOROV \\ Department of Finance and Credit \\ Yuriy Fedkovych Chernivtsi National University \\ Chernivtsi, 2 Kocyubynskogo St. \\ UKRAINE \\ GALYNA POCHENCHUK \\ Department of Economic Theory, Management and Administration \\ Yuriy Fedkovych Chernivtsi National University \\ Chernivtsi, 2 Kocyubynskogo St. \\ UKRAINE \\ ILONA BABUKH \\ Department of Marketing, Innovation and Regional Development \\ Yuriy Fedkovych Chernivtsi National University \\ Chernivtsi, 2 Kocyubynskogo St. \\ UKRAINE
}

\begin{abstract}
The article deals with key measures of establishing information and digital development of the Institute of Education in the conditions of innovativeness of Ukrainian economy. The reason that motivated the study was a number of pressing issues, such as the formation of a highly qualified specialist with new quality of digital competencies and skills based on an effective innovation and entrepreneurship university and the establishment of a quality institute of digital education in European digital educational environment, which remain little studied and need knowledge. Among the goals pursued by authors is to identify the prerequisites for accelerating the automation and digitization of the economy at different levels of economic aggregation and in terms of economic sectors; to present author's visualization of the potential innovative ecosystem of digital business center of the university in which applicants will be able to acquire digital practical skills. The purpose of the article is to investigate the peculiarities of modern problems of higher education in Ukraine, to consider objective conditions and current tendencies of development of information society. Methods: generalization in studying the nature of digital education; structuring - in explaining the prerequisites for reforming digital principles. Results. The scientific publication reviews the features of modern problems of higher education in Ukraine, including: lagging of scientific developments from needs of the economy, fragmentation of the use of distance learning technologies in economic specialties, inconsistency of the laboratory base of universities with a technical profile of the level of modern technologies. Scientific analysis of paradigm change in education of Ukraine is conducted. Authors' opinion is: changes are caused by integration processes in higher education system, democratization of the process of obtaining education, introduction of tools of freedom of choice of
\end{abstract}


resources, technologies. The originality of publication is that authors argue that a transformational change at the Institute of Education is a change from a passive system where learning is an audition, to an active learning system where students learn subjects/disciplines by sharing knowledge about these subjects. Value of the article is that authors outlined main areas of use of digital information technology in higher education, namely: development of educational websites and promising tools, teaching methods and technologies with a focus on development, promotion of personalized education. Conclusions. The article is devoted to the consideration of objective conditions and current tendencies of development of information society, which determine the course of automation and digitization of the provision of educational services in the conditions of innovativeness of Ukrainian economy.

Key-Words: information and digital development, higher education, informatization of the economy, informatization of education.

Received: February 20, 2021. Revised: June 4, 2021. Accepted: June 21, 2021. Published: July 7, 2021.

\section{Introduction}

The era of nanotechnology dictates its trends and sets trends. However, the question of what the world will be like in 10,20,30 years, how life will change in centuries, remains unanswered. Single futurists as fantasy, but every year the same future is getting closer perceive human futures.

All activities shift towards intelligence and the interaction of intellects. All global projects of the future are global collaboration networks. Therefore, working with such networks becomes important for the future. In the future, "middle-class" people are not needed, but highly specialized specialists are needed in the fields: complex problem solving, critical thinking, creativity, ability to manage people, interaction with people, emotional intelligence. This fact testifies only that in the future higher education may lose its prestige, and its development will be marked by a number of problems that today need regulatory regulation, in particular in terms of training specialists with digital skills, scientific and innovative activity, financing and modernization of material and technical base.

Therefore, the actualization of problems of information and digital development of higher education of Ukraine in the conditions of economic innovation is of particular urgency and requires finding a solution to this issue.

\section{Problem Formulation}

\subsection{Literature Review}

Among the scientists who started the study of digitalization as a phenomenon, include D. Tapscott and P. Samuelson. These issues quickly captured the scientific community and highlighted a large number of separate areas within which were considered some aspects of it. Names of foreign scientists V. Isaacson [1], P. Migram, F. Kisin are connected with the study of general aspects of reforming the Institute of Education in the direction of formation of innovative and entrepreneurial universities. Well-known researchers and economists Yu. Bazhal, V. Bazylevych [2], V. Vyshnevskyi [3], V. Heiets, Ya.Zhalilo, M. Zhurovskyi [4; 5], V. Kupriyanskyi [6], V. Osetskyi [2], A. Petrenko, A. Sukhomlyn, I. Tatomyr [2], etc. The problems of the use of ICT in the domestic system of education and the formation of digital and information and communication competences of students are devoted to the work of well-known scientists, through whom O. Baseluk [7], Yu. Bohachkov [8], V. Bykov [9], V. Dyvak [10], O. Spirin, O. Palchuk [9], V. Pozhuev [11], O. Pinchuk [12] and others.

Most of these researchers focus on the use of information technology in the preparation of teachers and teachers, the problems of introduction of electronic educational resources in the educational process, the study of theoretical and methodological foundations of the formation of multicultural competence of students and educators. But, at the same time, a significant number of problems, such as the formation of a highly qualified specialist with a new quality of digital competencies and skills based on an effective innovation and entrepreneurship university and the formation of a quality digital education institution within European digital learning environment, remain little studied and insufficiently disclosed by the above scholars.

It is these objective reasons that motivated us to dedicate this study to clarifying following issues, including: determining the prerequisites for accelerating the automation and digitization of the economy at different levels of economic aggregation and in terms of economic sectors; disclosure of 
meaningful features and modern tendencies of digital transformation and informatization of science and education of Ukraine; presentation of the directions of introduction of digital technologies in higher education and the expected results of their use and author's visualization of the potential innovative ecosystem of digital business center of the university in which applicants will be able to acquire digital practical skills.

Besides, we are living in a time of great transformation. All aspects of everyday life are radically changing. The world is becoming unrecognized and needs new approaches to the problems of economic development and growth. Not only are new state and business strategies needed, but also "a new way of thinking of the modern generation and a different level of education" [13, p. 247].

We are convinced that the new level of development of Institution of higher education is undergoing transformational changes in the part of its information and digital modernization. The dynamic development of information and communication technologies, including the cloudoriented ones, significantly influences both the process of higher education and its recipients. The use of digital technologies in the teaching of economics in higher education provides positive changes in the quality of economic knowledge gained, promotes the formation of professional competences.

\subsection{Purpose of the Article}

The purpose of the article is to reveal the peculiarities of new quality of development of the Institute of higher education in the part of its information-digital modernization in the conditions of innovatization of the Ukrainian economy and to present main directions of the use of informationdigital technologies in the field of higher education and objective conditions and current tendencies of development of the information society, digitization of the Institute of higher education, including: widespread adoption of blockchain technologies, the development of artificial intelligence, cloud computing and virtualization, public and hybrid ICT infrastructures, as well as the use of nebulous technology, chatbots and the use of electronic libraries in higher education.

\subsection{Tasks of the Article}

Among the main tasks of scientific research we can highlight: consider key measures of information and digital development of the Institute of Education in terms of innovation and digitalization of the economy of Ukraine; to review the problems of higher education in Ukraine, in terms of lagging behind scientific developments from the needs and demands of the economy, the fragmentary use of distance learning technologies in economic specialties, etc.; to carry out scientific analysis of change of a paradigm of education in Ukraine; consider transformational changes in the institute of education; to find out the objective conditions and current trends in the development of the information society, which determine the course of automation and digitalization of educational services; identify and justify the main areas of use of information and digital technologies in higher education.

\subsection{Methodology}

The methodological and methodical basis of this scientific work is based on a combination of structural-organizational and institutional approaches, which are used to study the issues of information and digital development of the Institute of Education in research, innovation and business universities. The following methods were used in the course of scientific research: analysis - in identifying existing in the scientific literature views on the essence of digital education and digital information technology in higher education; abstraction - when trying to isolate digital education from the environment of its origin and existence; synthesis and generalization - in structuring the prerequisites for reforming the principles of digital technologies and key areas of use of digital information technologies in higher education; comparison - when conducting a scientific analysis of the paradigm shift in education in Ukraine; subject-object analysis is used when considering the nature of the relationship in the field of university innovation ecosystem of digital business center.

\section{Problem Solution}

\subsection{Prerequisites for Automation and Digitization}

The analysis of normative documents, legislative acts and agreements signed between Ukraine and the European Union clearly show that main goals of the development of information society in our country are gradually being aligned with the vectors of European development. One of the most important documents is: Digital Agenda for Europe initiative; Europe 2020: Strategy for smart, sustainable and inclusive growth. These documents formed the basis of the project Digital Agenda for Ukraine 2020, which was presented by the Cabinet 
of Ministers of Ukraine and defines main priority positions of building the information society in our country on the basis of integration into the world processes of "digitalization" $[12 ; 14]$.

Having chosen the market vector for development, the Ukrainian higher school has set out to integrate into the world educational space. The desire to achieve these ideals has been and continues to be so influential and popular in domestic educational environment that it precludes thinking about a critical approach to analyzing the development of educational systems that has been determined to follow.

The fundamental technological changes that have taken place in recent decades have led to significant economic, and mainly social, changes. The main driver of such changes was the emergence and rapid spread of digital devices, as well as the widespread penetration of Internet, which affected all aspects of public life, including higher education [15, p. 13].

In keeping with World Economic Forum's forecast of the content of future professions and jobs, it should be noted that much of automation occurs at the level of specific jobs, not at the level of entire jobs. For example, according to a recent study by the same Forum, nearly two-thirds of today's jobs contain at least $30 \%$ of jobs that can be automated based on the technologies available today, but only about a quarter of jobs contain more than $70 \%$ of jobs that can be automated. Workforce automation will be played out in three waves between today and the mid-2030's, increasing the proportion of fully automated manual tasks to almost $40 \%$ in the most "affected" jobs today. Share of automated tasks involving social skills will increase similarly from $5 \%$ today, to about $15 \%$ in the future.

The most pressing issue for businesses, governments, and individuals is to strike a new equilibrium in the division of labour between human workers, jobs, and algorithms. The waves of automation have changed global economy throughout history. The first and second industrial revolutions combined specific work tasks into separate work roles, dividing work between humans and machines technologically available at that time. Changes and progress have led to productivity gains by "repackaging" jobs into new jobs, which has reduced the number of outdated job profiles and the growth of completely new activities, historically leaving a balance between job creation and economic value on the positive side.

However, the wave of Fourth Industrial Revolution and technological advancement will reduce the number of workers needed to perform some work tasks and increase the demand for the productivity of others. This process will require massive retraining and professionalism of the workforce on the one hand and, on the other, social protection on the part of those who have not found a high-tech workplace or who have been unable to develop.

Here is a list of activities that will primarily suffer from automation and digitization: Data entry clerks; Accountants and auditors; Administrators and Secretaries; Collectors and factory workers; Customer Support Services; Warehouse workers and custodians of securities; Post clerks; Financial analysts; Cashiers and ticket sales staff; Mechanics; Electronics repairmen and installers; Banking Agents and Related Sellers; Drivers; Sellers and sales agents; Lawyers; Insurers.

\subsection{Digital Transformation in the Education and Science Sector}

Education as a "social sieve" produces social stratification. Digital transformation in the education and science sector $[12 ; 16]$, usually not entirely misunderstood, as an electron, virtual education, or automation of a researcher's scientific activity, which greatly narrows the scope of the digital scientific-educational process.

The transition to digital relationship between teacher and student is the optimum relationship with images of electronic people and organizations that must be linked to uniquely identified subjects of the physical world and who work with digital educational documents using the latest educational technologies. In addition, education is a "temple" that legitimizes knowledge.

The current Ukrainian education system is undergoing significant changes due to the need to reform and change education paradigm. These changes are caused by integration processes in education, democratization of the process of obtaining education, introduction of tools of freedom of choice of resources, technologies.

A change in education is a change from a passive system where learning is to listen, to an active learning system where students learn subjects/disciplines by sharing knowledge of these subjects with each other. A change in educational system is a transition from a competitive system, where students compete for the best grades, to a cooperative system in which everyone helps one another as they study the disciplines. So, this is a transition from competition to collaboration.

Current problems of higher education in Ukraine are:

1) Low level of competences of the students in 
natural and mathematical disciplines;

2) Inconsistency of training of specialists to the needs of the labour market and slow reorientation on preparation of new, deficient for the labour market specialists;

3) Reduction of admission of specialists in the fields of STEM education due to the worsening demographic situation;

4) Significant lag of scientific development from the needs and demands of the economy;

5) Discrepancies in the laboratory base of universities with a technical profile of the level of modern technologies;

6) Lack of effective interaction between science, education and production in the context of exponential technologies;

7) Reducing the quality of the educational process;

8) Unequal access of urban and rural children to high-speed Internet and digital resources;

9) Uneven digitization of higher education in the context of different HEIs;

10) Dominance of solid skills over socioemotional and informational;

11) Fragmentation of the use of distance learning technologies in economic specialties;

12) Insufficient level of digital literacy of teachers;

13) Moral challenges of global digital society;

14) Inefficient organization of practical training of students-economists.

We agree with the opinion of researchers with S. Osipova, Yu. Tereshchenko and L. Klimovich, about new opportunities that are open to educational recipients and teachers as a result of informatization and digitization of the Institute of Education, in part:

- The application of a systematic approach to the organization of the educational process on the basis of structurally logical presentation of educational material, which allows defining the content in the form of a system of interconnected modules;

- Flexibility and openness of the educational process in relation to social and cultural differences between students, their individual styles, rates of study, their interests, which allows to increase the effectiveness of the educational process on the basis of its individualization and intensification;

- Intensification of the educational process on the basis of the multimedia form of submission of educational material, partial reduction of note taking of the text by receiving it in electronic form;

- Organization of interactive learning, built on the interaction of student with learning environment, which represents sphere of his experience and assimilated in the conditions of realization of his subjective position;

- Competence orientation of the educational process on the basis of a unified methodology for the use of information and digital technologies, which allow to integrate educational, research and independent types of students' activities. After all, this contributes to the formation of future specialists in the field of use of information technologies in the structure of professional competence, which in turn contributes to the development of competitiveness of graduates-economists of higher education institutions;

- Formation of a system of continuous education aimed at the sustainable development of the individual in a single information and digital space;

-Submission in the form of electronic educational materials (curricula, programs, notes, lectures, etc.);

- Creation of a favourable information environment for organizing the student's independent work on learning educational information at an individual pace and at a convenient time for him;

- Visualization of the content of discipline, demonstration of the studied phenomena and processes in development and dynamics [17].

Believing that the most successful learning can be considered where a student can obtain information on their own, but then interacting with one another by sharing, discussing, or applying it.

But main thing is the fact that digitalization provides a transition from "education for all - to education for everyone". This is evidence that a modern educational space is being built, which has all the conditions for mastering the basic (superprofessional) digital competencies and skills that are required by modern business.

Today, thanks to a well-organized digital environment, education is becoming more accessible and comfortable and produces knowledge in virtual reality, and this is important with minimal costs - time, financial, human resources and indepth knowledge and skills of modern digital technologies. In addition, for current generation of young people - this is also the usual comfortable environment - an environment of virtual, augmented and mixed reality. It is in such a modern educational environment that there are all the conditions for innovation and digital development, it is a kind of lifting to realize the individuality of each individual and the comfortable implementation of innovations [18, p. 92].

Digital technologies used in education have didactic potential. This potential provides the 
freedom to search for information of interest to the learner. The use of digital technologies allows the teacher to personalize information (it becomes focused on the needs of students, has varying degrees of complexity, the pace of material and methods of its presentation), to give it signs of interactivity, multimedia, subculture. This type of innovation forms a comfortable educational environment. The Institute of Education and Training, through the use of digital technologies, is becoming more flexible and accessible for students. ICTs provide new quality and conditions for distance learning and effective self-development and career growth.

\subsection{Informatization of the Education}

Informatization of education is a set of interrelated organizational-legal, socio-economic, educationalmethodical, scientific-technical, production and administrative processes aimed at meeting information, computing and telecommunication needs (other needs related to the implementation of methods and the means of information and communication technologies - ICT) of participants in educational process, as well as those who manage and provide this process (including its scientific and methodological support and development) [8].

Information and communication competence lies within the category of "interactive use of tools", which defines some key competencies (Figure 1).

The ability to interactively use language, symbolism, texts

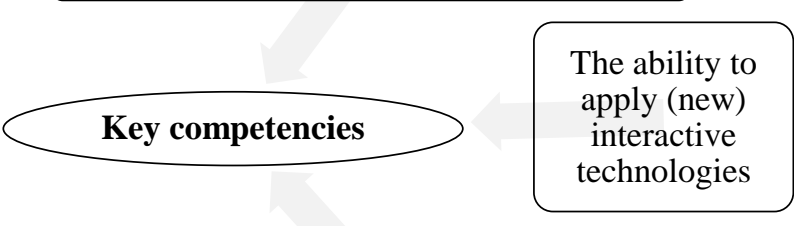

The ability to use knowledge (information literacy)

Fig. 1. Main information and communication competences

Source: summarized by authors based on 9, p. 10; 10, p. 6-8.

Digitalization is the saturation of physical world with electronic-digital devices, means, systems and the establishment of electronic-communication exchange between them, which in fact makes it possible to integrate virtual and physical, that is, to create cyber-physical space [11].

Digitalization the Institute of Education is a kind of paradigm shift in how we think, how we act, how we interact with the environment and with each other, and technology here is more of a tool than a goal. Digitalization helps to simplify educational process, making it more flexible, adapted to the realities of modern day, which in turn ensures the formation of competitive professionals.

In education, digitalization is aimed at ensuring the continuity of learning process, which is lifelong-learning - lifelong learning, as well as its individualization on the basis of advanced-learningtechnologies - advanced learning technologies.

The digitalization of education depends on the objective conditions and current trends in the development of the information society among which [7, p. 2-3]:

1) Development of artificial intelligence (Artificial intelligence), "machine learning" (Machine Learning), neural networks (Artificial Neural Networks);

2) Ensuring mobility of information and communication activities of users in the information space (Mobility), further development of mobileoriented tools and ICT access to electronic data;

3) Widespread adoption of Blockchain and Cryptocurrencies technologies;

4) Development of cloud computing and virtualization technology, enterprise, publicly available and hybrid ICT infrastructures, as well as introduction of technology of foggy calculations (Cloud Computing and Virtualization, Private, Public and Hybrid Clouds, ICT-infrastructures, Fog Computing);

5) Development of telemedicine (Telemedicine);

6) Development of new augmented reality features (Added Reality) and the availability of virtual reality equipment (Virtual reality);

7) Widespread introduction of Chat Bots and Virtual Assistants, the accumulation and processing of large amounts of digital data, the creation and use of electronic databases and systems (Big Data, Data Mining, Data Bases), including electronic libraries (Electronic Libraries, Repositories) and Scientometric Data Bases;

8) Development of user characteristics of the Internet of People (IoP), deployment of topology of broadband high-speed channels of electronic communications (Broadband Communication Channels), systems of formation of ICT-spaces of wireless access of users to electronic data (Cordless Access to Digital Data, Wi-Fi, Bluetooth, Cellular Networks);

9) Formation of the Internet of Things (IoT), development of its software and hardware, including microprocessors, and integration platforms, to 
provide for the setup, management and monitoring of electronic devices using modern telecommunications technologies;

10) Development of Robotics, robotic systems, in particular, 3D printers and 3D scanners;

11) Development of Software Development Industry, in particular, publication of electronic educational resources;

12) Compatibility of ICT tools and ICT applications built on different software platforms (Compatibility);

13) Development of networks of ICT service providers (ICT outsourcers market), primarily Cloud Services and Computing Center Network;

14) Development of Data Security and Counteraction of Cybercriminality.

\subsection{Digital technologies in higher education}

Main directions of the use of digital information technologies in the field of higher education and the characteristics of the result of the application of the new methodology in education are shown in Table 1.

Table 1. Areas of the implementation of digital technologies in higher education and the result of their use

\begin{tabular}{|c|c|}
\hline Main directions of the use of digital information technologies & The result of new methodology in education \\
\hline $\begin{array}{l}\text { 1. Purposeful search of information of various forms in global and } \\
\text { local networks, registration, collection, storage, storage, processing and } \\
\text { transfer } \\
\text { 2. Processing of the results of the training experiment } \\
\text { 3. Management of educational work } \\
\text { 4. Organizing and conducting computer experiments with virtual } \\
\text { models } \\
\text { 5. Implementation of automated control of the organization of } \\
\text { educational activities } \\
\text { 6. Development of pedagogical software for various purposes } \\
\text { 7. Development of methodological and didactic materials; } \\
\text { 8. Development of educational websites } \\
\text { 9. Increasing the efficiency of the educational process on the basis of } \\
\text { its individualization and intensification } \\
\text { 10. Development of promising tools, methods and technologies of } \\
\text { training with the focus on developmental, proactive personalized } \\
\text { education } \\
\text { 11. Achievement of the necessary level of professionalism in mastering } \\
\text { the means of computer science and computer technology }\end{array}$ & $\begin{array}{l}\text { 1. The ability to work in a team and } \\
\text { cooperate with each other } \\
\text { 2. To learn by interacting with society; } \\
\text { quality on-line courses } \\
\text { 3. An educational platform of highly } \\
\text { qualified teachers to ensure that every } \\
\text { student has access to the best teacher in the } \\
\text { world } \\
\text { 4. Mutual teaching that arouses interest in } \\
\text { the student to think } \\
\text { 5. Education in any language } \\
\text { 6. Working with a curiosity teacher rather } \\
\text { than a teacher who transmits information } \\
\text { that is freely available today, both through } \\
\text { paper and through electronic sources } \\
\text { 7. Preparing students for what they will need } \\
\text { to learn throughout their lives, that is, to } \\
\text { teach them to constantly learn and improve } \\
\text { 8. Passing a course of constructive } \\
\text { confrontation }\end{array}$ \\
\hline
\end{tabular}

Source: compiled by authors based on 19, p. 65

Digital format of the Institute of Higher Education more accurately represents the information, providing its free circulation, placement, processing, use in computer networks. Digital education system includes information resources, telecommunications, management systems, relationship of which is presented in Figure 2. Key measures for building information and digital development of the Institute of Education in the conditions of innovation of the economy are:

- A significant expansion of basic and applied research into various aspects of this problem, including those related to the use of cloud-oriented technologies, grid technology, artificial intelligence, etc. in the educational and scientific processes;

- Ensuring the formation and development of digital-digital competence of Ukrainian citizens in accordance with the European framework DigComp 2.0 and DigComp 2.1, enhancing their media psychological competence;
- Developing media literacy and a culture of networking for children and young people, ensuring the psychological well-being and rights of children and young people in co-operation with the open information space, in accordance with the recommendations of the Council of Europe;

- Intensification of the processes of designing and implementation of computer-oriented educational environments in educational establishments of different levels, as well as the widespread use of information and communication technologies in scientific activity, in particular by forming the corporate information infrastructure of scientific institutions and educational institutions;

- Improvement of distance learning systems with the use of different electronic educational platforms by creating electronic educational resources, adaptive learning technologies, electronic textbooks.

Nowadays, informatization and digitization are becoming an integral part of the educational process 
of higher education institutions, and the development of the infrared competence of modern teacher is a key issue in the implementation of educational reforms. We believe that a change in the educational paradigm should take place in the direction of change from a thematic center to a person-centered education.
Changes in the education system will result in the ability of the student to think creatively, to be able to solve problems, to manage life situations, to organize work, to manage their own growing experience and their own emotions.

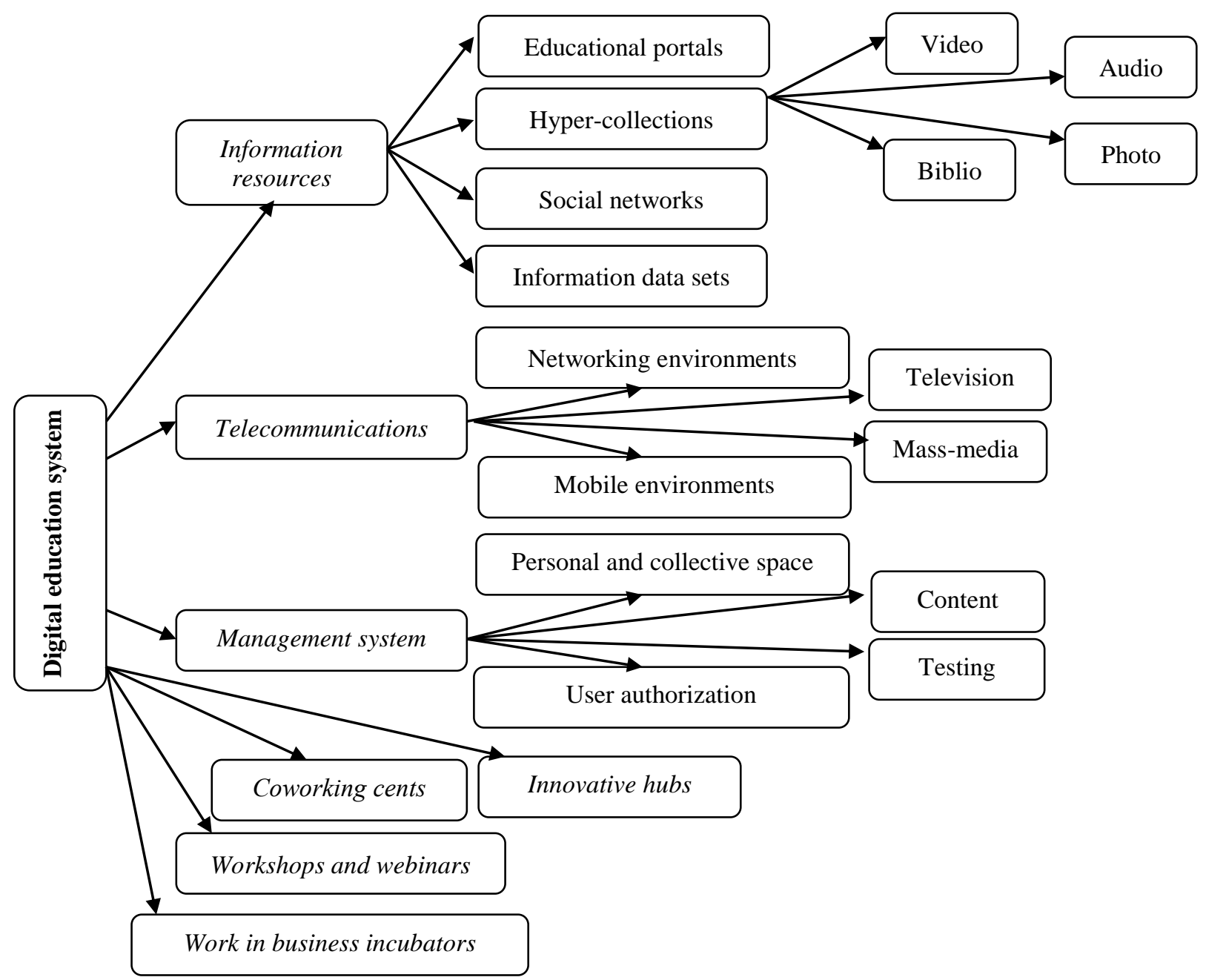

Fig. 2. Structural relationships between components in a digitized institution of higher education

Source: author's development

In Figure 2 we made an attempt to present structural relationships between the components of digital institution of higher education on a horizontal basis, which is realized through some functional grouping of the components of innovation and entrepreneurship university. Based on the above and within the problem of the article, we propose to consider qualitative those relationships between development institutions, which are presented in Figure 2, which are formed on the conditions of effective interaction of eeducation and e-science and provide the possibility of successful innovative activity of institutions of higher education and a set of interconnected, complementary systems, corresponding organizational and managerial subsystems necessary for effective implementation of innovation process.

The activity of all these structures is based on four defining principles: the maximum convergence of science, production, commerce; creation of the most favorable conditions for the development of science-intensive production, innovative business; associations of firms that develop and ensure commercial sale of various types of scienceintensive products and promote the accelerated exchange of scientific and technical information; formation of scientific conditions for the incubation period of formation of innovative firms, carrying out 
the first, most scientific stage of scientific and technical developments [20, p. 323-324].

However, the qualitative relationships and interactions presented in Figure 2 are possible with mutual openness; constant change and improvement through the project method of teaching, case methods, business simulations; promoting the development of individuals-innovators by creating comfortable moral and psychological conditions in the team working on innovative projects, and worthy financial rewards for innovators, scientists, researchers; conducting trainings and discussions with teams of entrepreneurs; expert analysis of innovative business projects; assessment of the competence of entrepreneurs in the field of innovation and their digital learning; assessments of prospects and capital intensity of projects.

Each of these development institutions in Figure 2 should be aimed at solving strategic problems and realizing potential competitive advantages, building high-quality interaction and relationships within the free economic zone, initiating innovation and digital development programs for various sectors of the economy with the involvement of organizations, specialists-innovators in various fields of science and technology. This type of structural components of free economic zone is the key to successful implementation of initiated projects of digital development of the country's economy. Key value in the interaction between those shown in Figure 2 institutes for the development of a digital institution of higher education free economic zones have such determinants as: mutual trust, partnership, use of a common information field, joint scientific and technical centers, marketing structures and sources of funding, support of local chambers of commerce and regional administration. Ensuring a high level of cooperation is impossible without clear legal rules governing the behavior of all subjects of the joint innovation network and their relations with external business structures and authorities.

In conclusion, it should be noted that a fundamentally new format of the educational environment is possible due to the development of a new quality of relationships between the components of digitized institutions of higher education, based on digital technologies that provide convenient and accessible services and platforms to increase competitiveness, more effective interaction of all participants, process, increasing its transparency and the role of intellectual property, the development of digital skills and competencies.

\subsection{Ecosystem of Innovation- \\ Entrepreneurial University}

The development of "digital" infrastructure and digital entrepreneurship is a matter of harmonizing initiatives and development programs of three levels: telecommunications infrastructure, data management, services and digital skills and competencies. Focus and resources on one or another level are determined by the priorities of development of "digital" ecosystem (Figure 3). Thus, digital regulator is a tool for harmonization and development of "digital" ecosystem.

Main goals of the ecosystem of the innovationentrepreneurship university, which we clearly show in Figure 3, are accelerated growth, modernization and improvement of competitiveness of key sectors of national economy, growth of new segments through better preparation for digitalization, innovation, new business models.

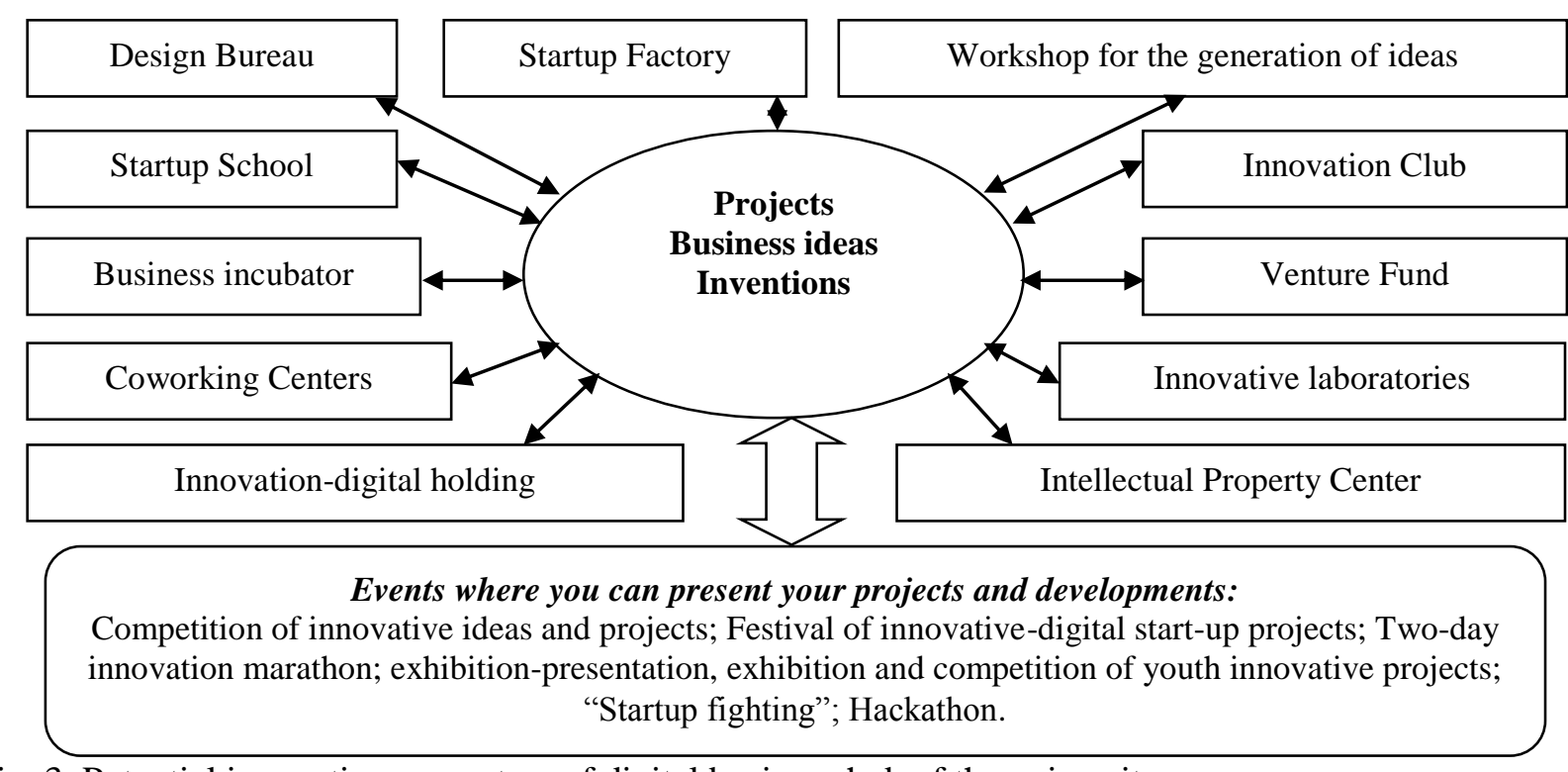

Fig. 3. Potential innovative ecosystem of digital business hub of the university

Source: author's development 
The work of the ecosystem (Figure 3 ) is aimed at introducing incentives and motivations for modernization, scaling and accelerating business development; encouraging businesses and citizens to consume and use information and communication and digital technologies. The ecosystem with the development institutions shown in the figure is designed to make digital infrastructures accessible, increase economic activity, create jobs, increase tax revenues and domestic demand, promote the modernization of obsolete assets and create new ones.

In addition, author's vision and understanding of the ecosystem is presented through its following components, namely: cluster, platform, ecosystem production; foundation of innovation laboratories, business incubators, parks, working on a full cycle; coworking cluster (co-working-office: start-upschool, start-up laboratory, start-up-accelerator, master classes of business school experts); Intellectual Property Center; digital education (Big Data School, BlockChain School, AI School, FinTech School, Idea Generation Workshop, Startup Factory).

In order to ensure the quality functioning of the innovation ecosystem, it is necessary to effectively launch accelerators of industrial high-tech, develop X.0 Centers, attract venture funds, grants, conduct timely ecosystem audits in order to timely monitor the innovation ecosystem.

Figure 3 shows how the structure of the ecosystem of the innovation-entrepreneurship university under the influence of open innovation, service prices, digital entrepreneurship, access to broadband Internet, takes form of a chain of type:

\section{"Developers-Owners-Providers-Advertisers- Regulators-Users".}

Innovative ecosystems of business universities form coordination centers, where universities and companies that form clusters meet within the framework of innovative cooperation (Figure 3). By working with small and medium-sized businesses and on startup projects, investors have the opportunity to eliminate inaccuracies in business ideas. During the functioning of the ecosystem, identify and bring to the attention of government officials" "bottlenecks" that exist in Ukrainian legislation.

The structure of the ecosystem within the innovation-entrepreneurship university may have the following working chain:

"Startup school-festival of innovative projects - business incubator - innovative technological environment - intellectual property center - venture fund".

A successful ecosystem of the innovationentrepreneurship university is a seamless process that requires flexible thinking and the creation of an organizational structure that will allow businesses to be involved in learning about digital trends, solutions and skills. The university's digital ecosystem solutions strategy is product/service oriented with the addition of information that provides new value to customers. Work with information at the innovation-entrepreneurship university can be represented by a chain such as:

"Search-obtaining-recognition-analysis-

filtering-enrichment-constructing informationapplication".

The functioning of the ecosystem is ensured by the availability of innovation resources (institutions, human capital and $\mathrm{R} \& \mathrm{D}$, infrastructure, market, business), stable mobility, mentoring, acceleration programs and aims at the result in the form of an innovative product (knowledge and technology, creative product).

Main features of the institutionalization of the ecosystem in the innovation-entrepreneurship university can be considered:

- Integration of the education system during the formation of Industry 4.0;

- Specificity and effectiveness in innovative laboratories of the university, working on the principles of entrepreneurship and digitalization, innovation;

- Realism and based on the interests and values of the main stakeholders;

- Reforming the institute of education with the aim of more open and practical communication, communication between educational institutions and higher education. We are convinced that schools should systematically hold presentations of the professions of the future, in order to form in young people a vision and vision of their future adult life. This is what will shape the digital culture of the digital entrepreneur;

- Strategic focus and relevance;

- Based on the best European and world experience of the education system and the market of innovations, digital products/services;

- Consolidation of stakeholders during the implementation of innovative and digital projects;

- The integrity of the institute of education.

In conclusion, it should be noted that the goal pursued during the study in the ecosystem of the innovative university is revealed through the 
implementation of the following issues:

- What to teach? (answer - for new digital competencies and skills);

- Why teach? (answer - to modern content);

- How to teach? (answer - effective digital technology);

- Where to teach? (answer - in a new space, a new augmented reality);

- Who should teach? (answer - teachers-coaches, mentors, teachers-practitioners in digital entrepreneurship);

- How to finance? (answer - adequate to the results);

- What is the end result? (the answer is the high "value" of the graduate in the labor market, a specialist with high quality competencies and skills in digital entrepreneurship).

\section{Conclusion}

We believe that one of the most effective methods of supporting and improving the quality of higher education in Ukraine should be the active cooperation of IT businesses with higher education institutions that train staff. Support should be multivector, have financial and programmatic aspects, namely, companies should provide financial assistance to Ukrainian universities, logistics to launch on their basis educational programs that best meet the requirements of the modern market, and sponsor student Olympiads.

The opportunity for personal development and professional growth remains important for students of economic specialties, which is why the need to use innovative teaching methods in the conditions of development of information-digital and telecommunication technologies is increasing today. In our opinion, internal educational initiatives should have several areas, including long-term training programs and individual lectures and workshops.

The topics of these initiatives should be focused on the harmonious development of employees and the accumulation of expertise within the company/enterprise: communication skills and teamwork, language learning, project management, technical initiatives. We are deeply convinced that digitization and informatization of the educational process is essential for the development of national society in general and young generation in particular.

Not only the informational educational technologies are important, but also their correct selection, combination and management in order to establish effective cooperation between the teacher and the student, their effective educational and scientific work. Benefits of digital transformation of the educational institution are obvious both to society in general and to each member in particular. Thus, we are talking, first of all, about the ability of information and communication technologies to improve content and quality of the Institute of Education, thereby providing favorable conditions for:

- Training in the most convenient conditions - at a comfortable pace, but with optimal use of time set aside to perform certain tasks;

- Development of skills to learn, to single out the most valuable material for self-development;

- Building an individual educational trajectory independently (anywhere, anytime, choose your own curriculum and teacher);

- Strengthening motivation for self-education and self-development;

- Formation of personality mobility, ability to quickly adapt to changing conditions unpredictably and rapidly;

- Reaching a diverse audience (content becomes personalized), ensuring cooperation and integration.

The introduction of such technologies into the education system in the conditions of becoming information and digital society is based on the use of computers and telecommunications, special equipment, software and hardware, information processing systems. Global digital environment has an impact on all spheres of public relations, but the educational sphere has a dominant influence. We have come to the conclusion that the classical forms of higher education should be harmonized and "adapted" to the requirements of the information society.

We have identified main manifestations of digitalization and informatization of education, namely: new means of acquiring knowledge, innovative technical resources for obtaining information; strengthening of national and international communication of educational and scientific sphere; the formation of new educational content and new forms of education, including distance education and virtual universities. We are convinced that the information society and the digitization of the Institution of higher education are complementary, interdependent phenomena.

The basis of modern high-quality higher education in Ukraine is its informatization as a set of interrelated organizational, legal, political, socioeconomic, scientific and technical, production processes that aim to create the conditions for meeting the information needs of citizens and society through the development and the use of 
information systems, networks, resources and digital technologies based on the application of modern computing and communication technology. We believe that updating the education system will help to revitalize scientific activity by attracting the younger generation. The need to use digital information technology encourages teachers and scholars to pursue professional development.

\section{References:}

[1] Isaacson V. (2017). Innovators: how a group of hackers, geniuses and geeks made the digital revolution. Kyiv: Nash Format Publishing House. (in Ukrainian).

[2] Bazylevych V., Osetskyi V., Tatomur I. (2019). Conformity of higher education with requirements of "digital natives", Bulletin of Taras Shevchenco National University of Kyiv. Economics, no. 1 (202), pp. 6-13. (in English).

[3] Vyshnevskyi V.P. (2018). Smart industry in the era of digital economy: prospects, directions and mechanisms of development. Kyiv: National Academy of Sciences of Ukraine, Institute of Industrial Economics. (in Ukrainian).

[4] Zgurovskyi M.Z. (2015). Digital Science in the Horizon 2020 Program. Systematic advances and information technologies, no. 1, pp. 7-20. (in Russian).

[5] Zgurovskyi M.Z., Petrenko A.I. (2014). Formation and horizons of digital science. Systematic advances and information technologies, no. 4, pp. 7-19. (in Russian).

[6] Kupriyanovskiy V.P., Sukhomlin V.A., Dobrynin A.P., Raikov A.N. (2017). Skills in digital economy and challenges of the education system. International Journal of Open Information Technologies, Vol. 5, no. 1, pp. 19-25. (in Russian).

[7] Bazelyak O.V. (2019). Digitalization of vocational education as a global socio-natural process. Information-digital educational space of Ukraine: transformation processes and development prospects. Kyiv. (in Ukrainian).

[8] Bohachkov Yu.M. (2012). Organization of the distance learning environment in secondary schools. Kyiv: Pedagogical thought. (in Ukrainian).

[9] Bykov V.Yu., Spirin O.M., Pinchuk O.P. (2017). Problems and tasks of the modern stage of informatization of education. Scientific support for the development of education in Ukraine: current problems of theory and practice, pp. 191-198. Kyiv: Sam Publishing
House. (in Ukrainian).

[10] Dyvak V.V. (2019). Development of economic competence of directors of general secondary education institutions by means of information and digital control technologies. Scientific support for the development of education in Ukraine: current problems of theory and practice. Kyiv: Sam Publishing House. (in Ukrainian).

[11] Pozhuev V.I. (2011). Ways and directions of formation and realization of modern information society in the conditions of globalization. Humanities Bulletin of Zaporizhzhya State Engineering Academy, Vol. 46, pp. 5-18. (in Ukrainian).

[12] Palchuk O.I. (2013). Innovative economy as a basis for development of modern society. Bulletin of the Kiev National University of Technology and Design, no. 1, pp. 247-252. (in Ukrainian).

[13] Goloborodko O. (2018). Digital economy: trends and prospects for the avant-garde character of the development, Effective economy, http://www.economy.nayka.com.ua/pdf/1_2018 18.pdf. (in Ukrainian).

[14] Osipova S.I., Tereshchenko Yu.A., Klimovich L.V. (2012). Fundamental education for the "digital generation". Modern problems of science and education, no. 5, http://www.science-

education.ru/en/article/view?id=6788.

(in Russian).

[15] Apalkova V.V. (2015). The concept of digital economy development in the European Union and prospects of Ukraine. Bulletin of the Dnipropetrovsk University. Series: Innovation Management, no. 23, pp. 9-18. (in English).

[16] Digital agenda of Ukraine 2020 ("Digital agenda" - 2020) (2016). Conceptual basis (version 1.0). Priority areas, initiatives, projects of "digitalization" of Ukraine by 2020", https://ucci.org.ua/uploads/files/ 58e78ee3c3922.pdf. (in Ukrainian).

[17] On approval of the Concept of development of the digital economy and society of Ukraine for 2018-2020 and approval of the plan of measures for its implementation (2018). Cabinet of Ministers of Ukraine, https://zakon.rada.gov.ua/laws/show/67-2018$\% \mathrm{D} 1 \% 80$. (in Ukrainian).

[18] Kucherak I.V. (2020). Digitization and its influence on the educational space in the context of the formation of key competencies. Innovative pedagogy. Theory and methods of 
vocational education, Issue 22 , Vol. 2, pp. 9194. (in Ukrainian).

[19] Bykov V.Yu. (2008). Models of open education organizational systems. Kyiv: Atika. (in Ukrainian).

[20] Androschuk H.O., Zhyliaev I.B., Chyzhevskyi B.H., Shevchenko M.M. (2009). Strategy of innovative development of Ukraine for 2010-2020 in the conditions of globalization challenges. Kyiv: Parliamentary Publishing House. (in Ukrainian).

\section{Contribution of individual authors to the creation of a scientific article (ghostwriting policy)}

Kateryna Kraus, research of digital transformation in the education and science sector, visualization of the presented material, drawing up a list of references.

Nataliia Kraus, formulation of the purpose and tasks of research, development ecosystem of innovationentrepreneurial university in terms of digitalization economy, selection of literature and its analysis.

Petro Nikiforov, determination of the methodological apparatus of the research and evaluation digital technologies in higher education.

Galyna Pochenchuk, writing an annotation of scientific research and highlighting the essence of the informatization of the education.

Ilona Babukh, disclosure of the issue of prerequisites for automation and digitization and generalization of research results into conclusions.

\section{Sources of funding for research} presented in a scientific article or scientific article itself

Financing at the expense of authors (self-financing)

\section{Creative Commons Attribution}

\section{License 4.0 (Attribution 4.0}

International, CC BY 4.0)

This article is published under the terms of the Creative Commons Attribution License 4.0

https://creativecommons.org/licenses/by/4.0/deed.en US 